\title{
Síndrome de Hipogrifo
}

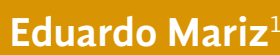

1 Doutorando e mestre em artes pelo PPGARTES/UERJ. Possui especialização lato sensu em fotografia pela UCAM/RJ. Em sua pesquisa e nas propostas artísticas, por meio fotografias ou performances, trata de medidas de tempo e espaço distintas às do cotidiano. Procura evidenciar mundos periféricos e ergonomias invisíveis. Sustenta que por tais deslocamentos são possíveis assimilações efetivas dos mundos, cabendo tal apreciação como estímulo efetivo no campo educacional e vivencial. Universidade do Estado do Rio de Janeiro (PPGARTES/UERJ). E-mail: edumariz8@gmail.com. ORCID: https://orcid.org/0000-0002-0990-5020. Lattes iD: http://lattes.cnpq. br/9504060744990245. Rio de Janeiro, Brasil. 
Eu estava a caminhar pelas matas de um lugarejo chamado Matutu, em Minas. Era hora do crepúsculo, mas a vegetação fazia o ambiente mais escuro que o normal. Dei de cara com a égua desgarrada (acho, pois o que estaria fazendo numa clareira inóspita?). Como se fosse um pet, ela começou a rolar no chão a minha frente. Parecia fazer festa. Sua pelagem era tão branca que seu corpo, como que dotado de uma luz própria, viabilizou o contraste obtido nas fotografias.

Acredito em buscar nas metalinguagens recursos cabíveis às fases onde prevalecem as incertezas. Sobretudo em arte. Um retorno aos arquétipos, ao originário, para a partir de então se entender os processos e as vivências.

A ideia de duração, estruturada por Bergson, seria a completude do mundo como processo. Mas nós percebemos o mundo por resumos, por fragmentos, limitados pelas nossas capacidades físicas. ${ }^{1}{ }^{2} \mathrm{O}$ tempo é absolutamente contínuo, tal qual a nossa consciência, mas o fluxo dessa não obedece a padrões organizados aplicados à nossa vida prática. Compartimentamos o tempo (e a consciência) para atender necessidades em lidar com conhecimentos e com as demandas sociais. $O$ conhecimento como entendemos não está talhado para esse tipo de continuidade. ${ }^{3}$ Segundo Bergson, para compreendermos de maneira efetiva os devires da realidade devemos apelar para a intuição, pois essa sim se dá num fluxo contínuo. A intuição é uma apreensão direta das coisas. Também seria um tipo de conhecimento, mas não o objetivo e sim o empírico. Por certo, através da intuição acontece a assimilação ideal de uma obra de arte.

O conceito de intermitência do tempo como modo de perceber o movimento, apregoado como uma falsa sensação é um fato que veio a ser comprovado pelo cinema. É o cinema, materialmente, a prova de que dessa maneira percebemos o movimento. Ao assistirmos aos seus dispositivos acionados (quando projetados os filmes), enxergamos o movimento. Ao

1 Henri Bergson, francês, filósofo (1859-1941).

2 Bergson, Henri; Matéria e Memória. Ensaio sobre o corpo e o espírito. São Paulo: WMF Martins Fontes; Edição: 4a 2010.

3 Franklin Leopoldo e Silva é Livre-docente e doutor em filosofia pela USP, onde também é professor de História. Palestra disponível em: https://www.youtube.com/watch?$v=x l h 2 h Q h A r n 4 \& t=1 s$. Consulta 06/04/2020. 
segurarmos na película não; mas sim a constatamos apenas como sequências de fotografias. ${ }^{45}$

O movimento, também é contínuo e imanente, tal qual é o tempo e a consciência, e impossível de ser reproduzido. E nas sequências de imagens que criamos para visualizá-lo sempre haverá passagens ocultas. Entre uma imagem e outra sempre haverá um lugar escuso, talvez propício a alojarem-se ali subjetividades, subliminaridades ou estruturas do invisível.

Certo é, contudo, que para nosso entendimento temos a fotografia como matriz da compreensão de movimento. Por esse sentido, é passível também a leitura da fotografia como ente promotor da eterna presencialidade, que nos permite trazer às nossas medidas de tempo, elementos que se eternizem enquanto tal, para assim os compreendermos e os revermos tantas quantas vezes forem precisas.

Radicalizando esse entendimento, poderíamos assinalar por sínteses a ideia de duração. Ao suprimirmos ao máximo essas sequências fílmicas, teríamos em duas fotografias sequenciais ou mesmo espaçadas em tempo e distância, elementos mínimos para descrever um segmento de movimento? Acredito que sim, ao menos em poéticas por mim promovidas, como no caso das imagens em foto-assemblage. Segundo convenções da geometria, bastam dois pontos para se definir um segmento de reta ou, de maneira consequente, a própria reta. Teríamos nos trabalhos em foto-assemblage a possibilidade em oferecer em imagens únicas e estáticas correspondentes a grandes dilatações de espaço, tempo ou de transitares entre consciências. Conjunturas das quais o olho humano não daria conta por suas limitações físicas. Cogito, contudo, que, como pelos mesmos meios falseados, mas que em nós intuem o movimento, a foto-assemblage nos forneceria a compreensão de deslocamentos contínuos, mas apresentados integralmente como constantes. Assim, nos forneceria uma possível maior consciência acerca do tempo contínuo. Isso é cabível exatamente por estarem as imagens em foto-assemblage em distinta escala de tempo da cotidiana, que seria o tempo cristalizado da fotografia.

4 Deleuze, Gilles; Imagem e Movimento; Consulta a PDF disponível em: https:// conexoesclinicas.com.br/wp-content/uploads/2015/12/DELEUZE-Gilles.-Cinema-a-imagem-movimento1.pdf . 18/04/2020. P.6.

5 Deleuze, Gilles; Bergsonismo; São Paulo: Editora 34; Edição: 2, 2012 
Entre as experiências em foto-assemblage, a série Não domesticados versa sobre as referências elementares que carregamos e caminhos percorridos em tentativas de busca-las: Por um instante fui uma mula encilhada. $A$ cabeça que se perde na escuridão, encontra aporte numa criatura doutrinada no almejado mundo onde seria, por fim, livre.

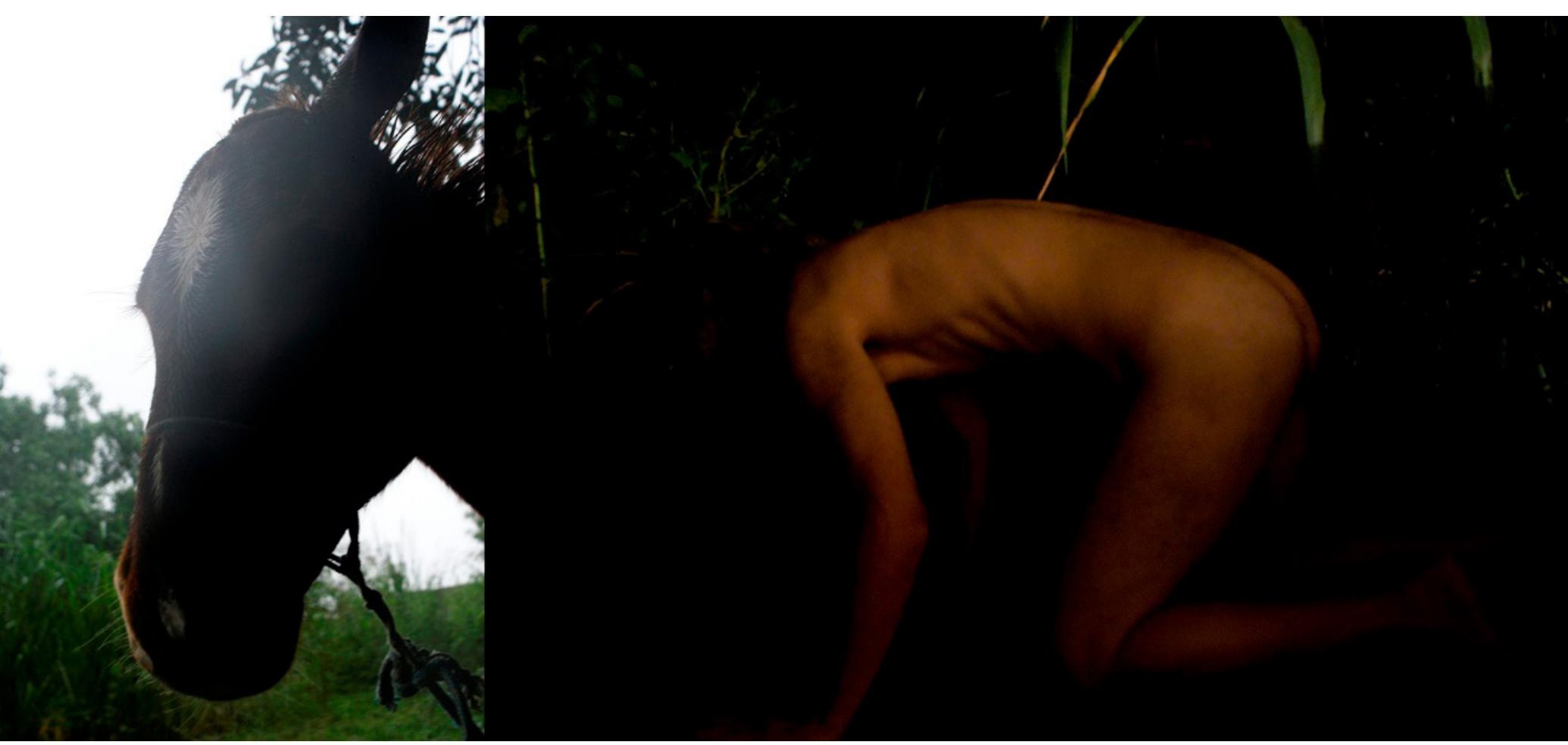

Figura 1 Da série Não domesticados $\mathrm{n}^{\circ} 2$; 2011; foto-assemblage; $55 \times 120$ $\mathrm{cm}$. Créditos do autor.
Complementando as considerações introdutórias, cabem também observações acerca do que foi assinalado por Bachelard em sua obra A Poética do Espaço. ${ }^{6}{ }^{7}$ Teríamos numa definição ampliada que o termo poética do espaço para o filósofo é a instauração do espaço pelo modo poético. ${ }^{8} \mathrm{O}$ espa-

6 Gaston Bachelard, francês, filósofo (1884-1962).

7 Bachelard, Gaston; A Poética do Espaço; São Paulo: Martins Fontes, 2008. P.199. Consulta ao PDF disponível em: https://drive.google.com/file/d/1ohu-3gLS5fk05eDap ZbHzdpyuw7AqLo/view . 07/04/2020. P.16.

8 Em palestra proferida por Nichan Dichtchekenian, psicólogo e professor de Fenomenologia e Psicologia Fenomenológica na PUC-SP. Disponível em https://www.youtube. com/watch?v=QPFGvuY8c_A. Consulta 06/04/2020.

Recebido em 19 de abril de 2020 e aceito em 04 de junho de 2020. 
ço para Bachelard é aquilo que poeticamente nós vivemos na nossa presença no mundo; que tem por natureza haver sempre uma distância entre o eu e.... O filósofo trabalha isso partindo desse sentido. O poeta (e por analogia, o artista) faz essa reflexão vivendo das imagens, que Bachelard chama de imagens poéticas. Na imaginação poética, o passado cultural não conta, deve-se esquecer o seu saber. Se há uma filosofia da poesia ela deve nascer e renascer por um verso dominante, na adesão total a uma imagem isolada muito precisamente no próprio êxtase da novidade da imagem. Resumo: jogar fora toda a bagagem, pois ela (a imagem) pede um contato ingênuo.

Pelas imagens em foto-assemblage se construírem a partir de duas fotografias, em tessituras, sugestiono suas compreensões como segmentos de percursos, onde temos seus eventuais observadores impelidos a buscar caminhos que relacionem essas fotografias que usei, criando vínculos a partir de seus próprios afetos que garantam tal continuísmo. Essa conduta contemplativa, acredito, pleiteia a intuição sugerida por Bergson e a ingenuidade de um primeiro olhar proposta por Bachelard.

Figura 1

Dalton Paula, $A$ cura, 2016 (Detalhe. Créditos: Paulo Rezende).

\section{Além do Horizonte de Eventos}

Considerando termos a fotografia como elementar na compreensão de movimento e agente promotor de movimentos assimiláveis, seria ela por si, sozinha, também capaz de orientar um movimento na sua completude?

Proponho que sim, mas no que seria outra forma de assemblage: não entre dois objetos ou duas fotografias, mas sim onde acontece o assentamento de uma imagem com uma ação.

Somente na ação combinada com a imagem, seria possível entender um movimento como tal. Talvez movimentos existam apenas a serem intuídos, e assim percebidos em toda seu aspecto de imanência. Não movimentos perceptíveis pelos olhos, mas sim pela aludida intuição.

Assim adentramos aos trabalhos do grupo Além do Horizonte de eventos. Proponho planos onde, talvez, incertezas se acentuem procurando fomentar sentidos ampliados.

Imersos na enxurrada de questionamentos sobre fatos ou falsidades daquilo que circula no ciberespaço e nos meios jornalísticos, caberia uma reflexão acerca do próprio conceito sobre o mundo visível. E teríamos talvez 
Figura 2

Isaka e Ibã Huni Kuin, Nai basha masheri, 2014. nas verdades do sensível as últimas inquestionáveis, ainda que limitada a universos pessoais.

Em que isso envolve a fotografia? Em termos técnicos temos que aquilo que nos mostram as fotografias, de fato aconteceu. A despeito de ser uma situação espontânea ou encenada, servindo a um trabalho documental ou artístico, aquilo captado por uma lente, de fato esteve ali diante dela. Por esse princípio aquilo que é apresentado numa fotografia, tendenciosamente seria aceito como verdade.

Contudo, sabemos que pouco depois de inventada a fotografia perdeu seu pretenso atributo de produzir imagens verídicas do mundo. A intermediação entre a captura e a imagem sempre é atravessada pela intenção do fotógrafo, e isso logo se evidenciou. Viabilizou-se, contudo, por esse mesmo princípio, o desenvolvimento da fotografia como meio artístico.

Os trabalhos da linha que aqui apresento versam com constatações poéticas acerca das relações entre as verdades condicionadas ou normatizadas pelo homem, as verdades da natureza e as verdades da arte; não por acaso usando o meio da fotografia.

Assim, sugiro que compreender a fotografia como arte é situá-la num campo onde as verdades do sensível dialoguem com a ideia de uma ação performática do fotógrafo. Haverá de ser enaltecidos fatores extraquadro-imagético que conduzam o observador a adentrar em referências para enfim manifestar suas verdades: aqui, as verdades da arte.

$\mathrm{Na}$ astronomia, o termo Horizonte de Eventos se refere ao limite que circunda os buracos negros, a partir do qual nada (nem mesmo a luz) escapa da violenta atração magnética. Áreas onde as leis da física como as conhecemos não são aplicáveis. Teríamos então verdades questionadas?

Seguindo esse entendimento, arrolo entre os trabalhos desse grupo, a série Síndrome de Hipogrifo ou Porquê equinos e pássaros nunca se deitam.

Não houveram manipulações em imagens da série Síndrome de Hipogrifo, onde apenas algumas fotografias tiveram suas polaridades invertidas ou sofreram alguns cortes. As incluí como exemplos de assemblages por proporem montagens imagéticas que se processem em lugares externos à própria materialidade da imagem, entre a imagem autônoma e uma ação (ou não ação) sobre ela. 


\section{Síndrome de Hipogrifo ou Porquê equinos e aves nunca se deitam}

Figura 2

Síndrome de Hipogrifo ou

Porquê equinos $e$ aves nunca se deitam $\mathrm{n}^{\circ} 3$; 2019; fotografia digital impressa; medidas: $110 \mathrm{x}$ $182 \mathrm{~cm}$ ou $20 \mathrm{x}$ $30 \mathrm{~cm}$. Créditos do autor.

Figura 3 Síndrome de $\mathrm{Hi}$ pogrifo ou Porquê equinos e aves nunca se deitam no 4; 2019; fotografia digital impressa; medidas: $110 \times 182 \mathrm{~cm}$ ou 20 x 30 cm. Créditos do autor.
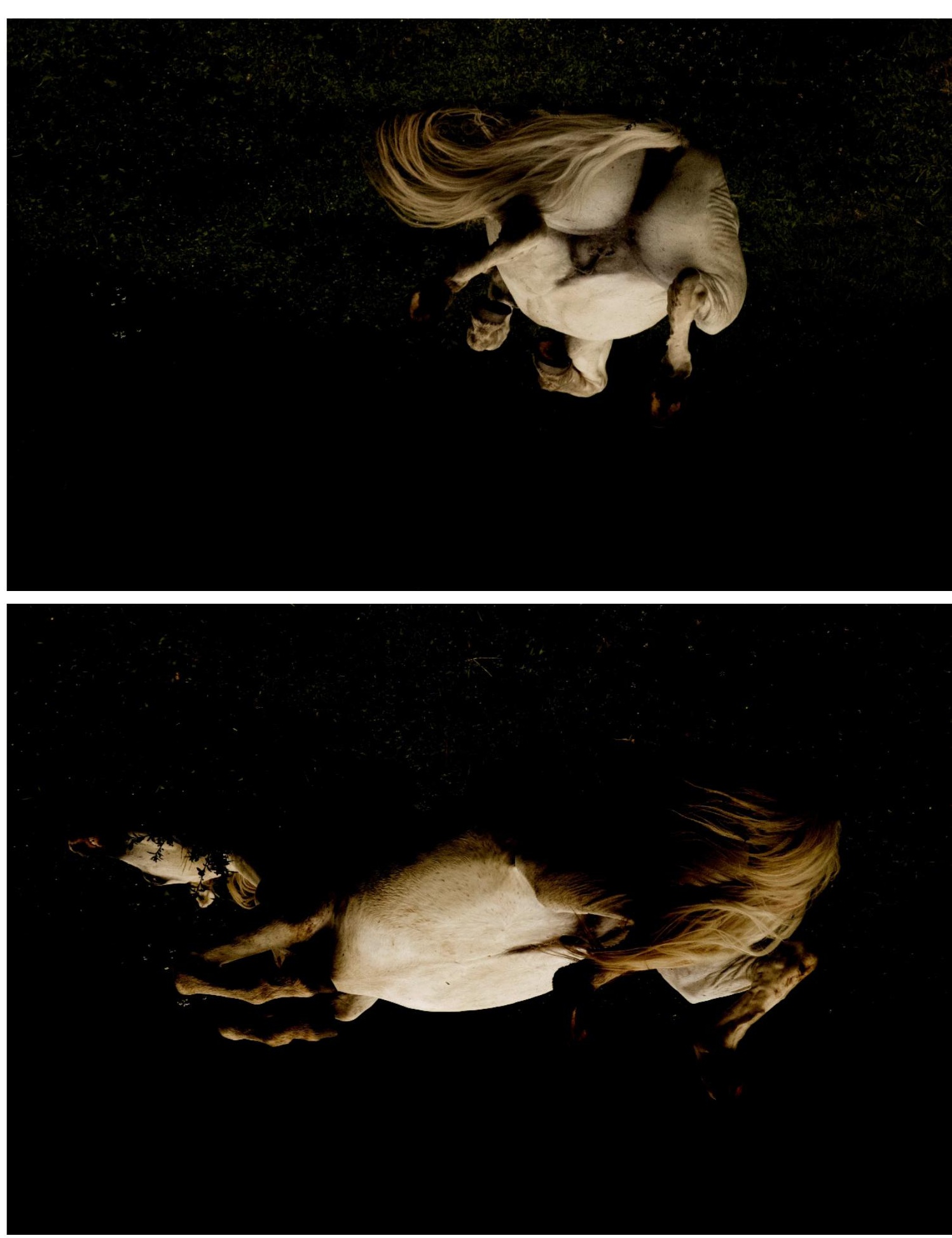

Galope inverso. Égua como água-nuvem.

Flutuante massa possível no imaginário, construção de imagem.

Um não-haver-o-tempo em instantes imersos em espaço. Lugar onde o em cima e o embaixo são convenções e ideais de escalas a serem revistas. Dimensões Alquímicas, Anímicas, Arquetípicas. Embate do corpo com o chão, salto para mediações geofísicas. 
A série Síndrome de Hipogrifo fala da observação de corpos em embates metafísicos, superando as convenções sobre massa, gravidade e horizonte nas leituras de imagens.

A partir da crença popular de que cavalos e éguas nunca se deitam, criei o grupo de seis imagens compreendidos por Síndrome de Hipogrifo. Nele procurei tecer poética que viesse a provocar um vislumbre através de uma crítica sutil sobre uma pretensa eficiência acerca das imposições da vontade do homem à natureza. A polaridade de algumas fotografias desse grupo foi invertida de maneira que o animal registrado sempre apareça de pé. Em momentos flutua num galope como uma nuvem. Assim percebemos díspares conceitos de verdade nessas fotografias. Só fotografamos aquilo que existe: a égua existe de fato. A égua não aparece deitada, ainda que observemos a falácia descarada das fotos invertidas. A égua voa.

A figura mitológica do híbrido animal Hipogrifo (misto de cavalo, ave e felino) poderia estar a nos dizer algo sobre aspectos que distintas espécies de animais possuem em comum. A ideia de que pássaros nunca se deitam, tal qual os equinos os colocariam como parentes? Poeticamente, contudo, semelhanças podem complementar limitações em imaginários híbridos, onde, por fim, verdades artísticas se estabelecem. Animais alados como Hipogrifo ou Pégaso voam. São equinos e são pássaros. Aquilo que seus originários possuem em comum, se complementam no mito: como um homem poderia cavalgar numa águia?

Figura 4 Síndrome de Hipogrifo ou Porque equinos e aves nunca se deitam $\mathrm{n}^{\circ} 1$; 2019; fotografia digital impressa; medidas: $110 \times 199 \mathrm{~cm}$ ou $20 \times 30 \mathrm{~cm}$. Créditos do autor.

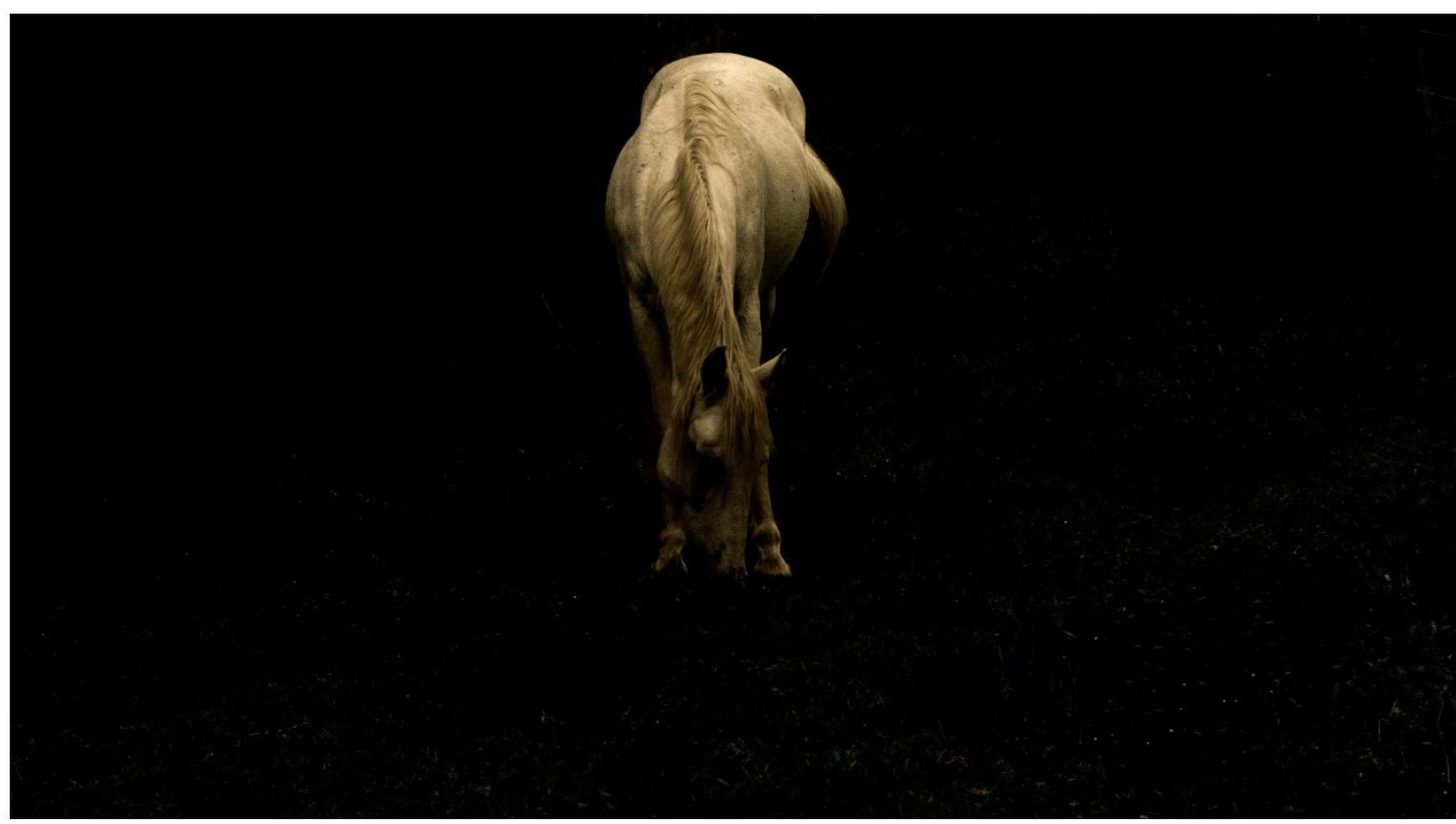


Figura 5

Sindrome de Hipogrifo ou Porquê equinos e aves nunca se deitam $n^{\circ} 2$; 2019; fotografia digital impressa; medidas: $158 \times 110 \mathrm{~cm}$ ou $30 \times 20 \mathrm{~cm}$. Créiditos do autor. 
Figura 6

Síndrome de Hipogrifo ou Porquê equinos e aves nunca se deitam $\mathrm{n}^{\circ}$ 5; 2019; fotografia digital impressa; medidas: $121 \times 110 \mathrm{~cm}$ ou $30 \times 20 \mathrm{~cm}$. Créditos do autor.

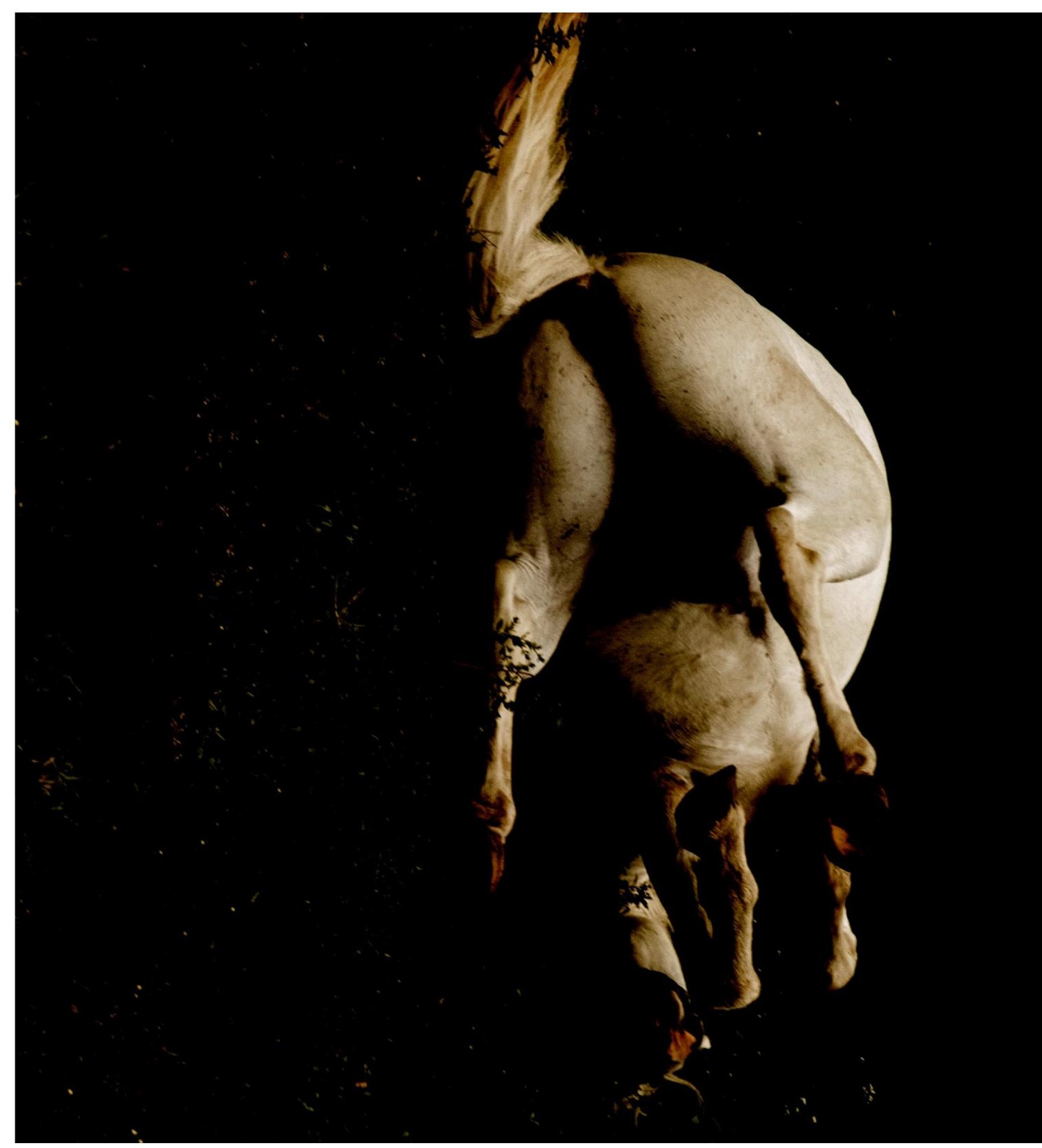




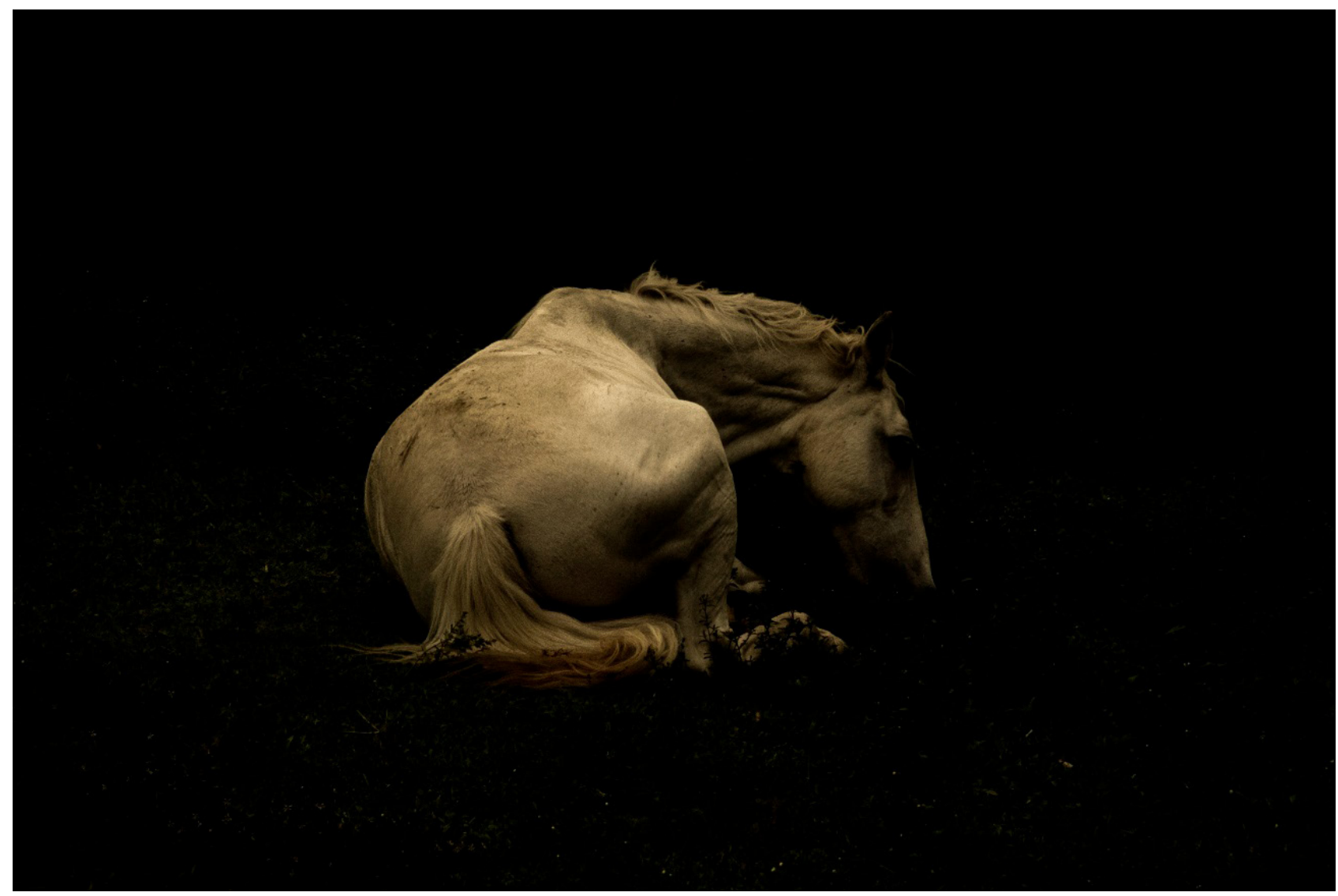

Figura 7

Síndrome de Hipogrifo ou Porquê equinos e aves nunca se deitam no 6; 2019; fotografia digital impressa; medidas: $110 \times 165 \mathrm{~cm}$ ou $20 \times 30 \mathrm{~cm}$. Créditos do autor.

Recebido em 19 de abril de 2020 e aceito em 04 de junho de 2020

Este é um artigo publicado em acesso aberto sob uma licença Creative Commons $(\mathbf{c c}) \mathbf{B r}$ 